\title{
DESENVOLVIMENTO DE GEOPOLÍMEROS A PARTIR DE CINZAS PESADAS POR ATIVAÇÃ̃O ALCALINA
}

\author{
R. A. ANTUNES BOCA SANTA ${ }^{1}$, J. NONES ${ }^{1}$, H. G. RIELLA ${ }^{1}$, N. C. KUHNEN ${ }^{1}$ \\ ${ }^{1}$ Universidade Federal de Santa Catarina, Departamento de Engenharia Química e \\ Engenharia de Alimentos \\ E-mail para contato: roosebs@yahoo.com.br ${ }^{1}$, janaina.nones@posgrad.ufsc.br ${ }^{1}$, \\ riella@enq.ufsc.br ${ }^{1}$, nivaldo@enq.ufsc.br ${ }^{1}$
}

\begin{abstract}
RESUMO - Este trabalho trata do desenvolvimento de um material cimentício a partir de aluminosilicato $\left(\mathrm{Al}_{2} \mathrm{O}_{3} \cdot \mathrm{SiO}_{2}\right)$ amorfo, denominado geopolímero. Cinzas pesadas foram utilizadas como fonte de aluminossilicato, os ativadores utilizados foram hidróxido de sódio $(\mathrm{NaOH})$ e silicato de sódio $\left(\mathrm{Na}_{2} \mathrm{SiO}_{3}\right)$. As propriedades químicas da cinza pesada foram determinadas por fluorescência de raios $\mathrm{X}$, e as propriedades estruturais por difração de raios X; também foram realizados testes de microscopia eletrônica de varredura e resistência à compressão mecânica. Os principais resultados mostraram que para ocorrer a geopolimerização é necessário que haja um ajuste entre as razões molares do material sólido a base de aluminossilicatos e as razões molares entre os ativadores utilizados. As cinzas pesadas ativadas obtiveram resultados satisfatórios na síntese de geopolímeros. No entanto, a cinza pesada por perder parte de seu estado amorfo deve ser avaliada, pois o tempo de cura foi mais longo quando comparado com outras pesquisas sobre materiais geopoliméricos.
\end{abstract}

\section{INTRODUÇÃO}

Atualmente há um forte interesse na utilização de resíduos industriais como matéria-prima para novos produtos, a fim de atender a demanda do mercado e fornecer opções tecnológicas ambientalmente sustentáveis. Pois com o aumento da população mundial agrava o consumo de matérias-primas renováveis, bem como a produção de resíduos (TORGAL e JALALI, 2011). Tendo em vista o grande montante de resíduos industriais, disponíveis para serem tratados, e que muitas vezes podem servir de matéria-prima com baixo custo, foram realizados estudos sobre os mecanismos de reação para o desenvolvimento de novos sistemas ligantes, obtidos por ativação alcalina de aluminossilicatos amorfos.

Uma abordagem tecnológica é o desenvolvimento de um polímero inorgânico, chamado geopolímero, com uma estrutura baseada em polissialatos. O termo geopolímero foi criado por J. Davidovits, em 1979, para designar as propriedades químicas do material. A polimerização ocorre por meio de uma reação química rápida em condições fortemente alcalina. A estrutura dos

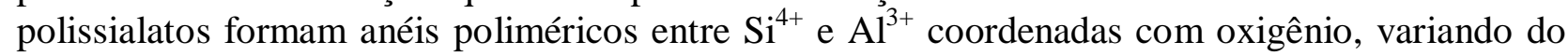
estado entre amorfo e semicristalino. Os geopolímeros são resistentes ao ácido e ao fogo; têm propriedades semelhantes às zeólitas, são úteis para a contenção de resíduos tóxicos; sua liga possui excelente trabalhabilidade e são curados rapidamente em baixas temperaturas (Davidovits, 
2002). Muitos estudos mostram a reatividade dos aluminossilicatos amorfos, presentes em materiais naturais ou materiais que tenham sido submetidos a tratamento térmico, como por exemplo, as escórias de alto forno, cinzas leves e pesadas, resíduos de construções, cinzas vulcânicas, metacaulim, entre outros. Xu e Van Deventer (2000) apud Komnitsas (2007) relatam que os materiais que sofreram tratamento térmico modificam parte de sua estrutura, em estruturas amorfas, esse processo que aumenta o potencial reativo devido às reservas de energia armazenada no processo.

Neste trabalho a formulação geopolimérica foi preparada com cinzas pesadas da queima de carvão mineral, resíduo gerado em uma termoelétrica, situada no Estado de Santa Catarina, Sul do Brasil. As cinzas pesadas apresentam propriedades pozolânicas devido ao tratamento térmico que o carvão foi submetido durante a queima, formando através deste processo, um percentual atrativo de aluminossilicatos amorfos, o que favorece as reações químicas durante a ativação e formação geopolimérica (Pinto, 2004).

Portanto, o objetivo deste estudo foi o desenvolvimento de geopolímeros a partir de cinzas pesadas, ativadas com hidróxido de sódio e silicato de sódio, para avaliar o potencial das cinzas pesadas, como matéria-prima sólida principal, na síntese de polímeros inorgânicos ou geopolímeros.

\section{MATERIAIS E MÉTODOS}

A cinza pesada foi submetida à secagem em estufa durante 24 horas a $100{ }^{\circ} \mathrm{C}$, e em seguida passou por moagem em um moinho de bolas, durante 8 horas, para ajustar o tamanho de partículas. A análise da composição química da cinza pesada foi realizada por meio de FRX, realizados em um Espectrômetro da marca Philips, modelo - PW 2400, por dispersão de comprimento de onda (WDXRF).

Como ativadores foram utilizados hidróxido de sódio $(\mathrm{NaOH})$ com $97 \%$ de pureza e silicato de sódio $\left(\mathrm{Na}_{2} \mathrm{SiO}_{3}\right)$, na proporção de 3,3:1 $\left(\mathrm{SiO}_{2} / \mathrm{Na}_{2} \mathrm{O}\right)$. As proporções de silício e alumínio foram utilizadas de acordo com a disponibilidade da cinza pesada. Conforme os dados da Tabela 1, onde estão descriminados os valores em óxidos da composição química das cinzas pesadas utilizados neste estudo, sendo a razão molar obtida 2,65 $\left(\mathrm{SiO}_{2} / \mathrm{Al}_{2} \mathrm{O}_{3}\right)$. A concentração de $\mathrm{NaOH}$ foi preparada a $15 \mathrm{M}$. A razão molar de $1,6\left(\mathrm{SiO}_{2} / \mathrm{Na}_{2} \mathrm{O}\right)$ foi determinada na mistura entre o silicato de sódio e o hidróxido de sódio. A relação entre $\mathrm{H}_{2} \mathrm{O} / \mathrm{Na}_{2} \mathrm{O}$ utilizado foi de 14,28 , sendo que a água utilizada no processo corresponde à fração de água utilizada na preparação dos reagentes. Para o preparo das amostras, as proporções de cinza pesada e os reagentes foram misturados, e em seguida procedeu-se agitação mecânica, por cerca de 5 minutos, para total homogeneização da mistura. As amostras foram então moldadas em recipientes plásticos com um volume de $196 \mathrm{~cm}^{3}$, conforme demonstrado na Figura 1.

Após a cura de 90 dias, as amostras foram analisadas por microscopia eletrônica de varredura (MEV), em aparelho da marca Phillips XL30 - da marca JEOL JSM-6390LV Scanning Electron Microscope, com o objetivo de obter a caracterização morfológica e química dos materiais. As análises de difração de raios $\mathrm{X}$ (DRX) foram realizadas e em um difratômetro Philips, modelo X'pert, com radiação cobre $\mathrm{K} \alpha(\lambda=1,5418 \mathrm{~A})$.

A fim de determinar o comportamento mecânico, foram realizados testes de resistência à 
compressão. As amostras foram sintetizadas em triplicata, e em intervalos de tempo diferentes, durante 30 e 90 dias.

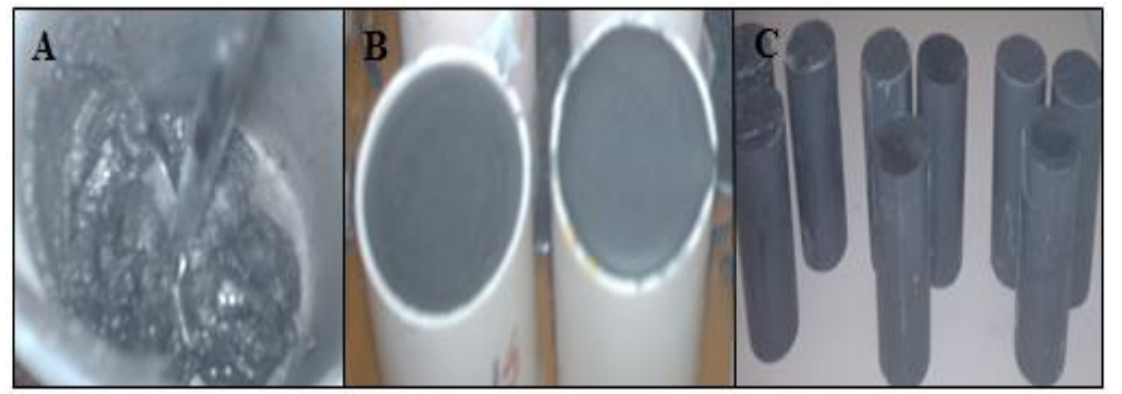

Figura 1: (a) mistura da cinza pesada e ativadores; (b) observação da pasta geopolimérica sendo curada em recipientes plásticos cilíndricos; (c) amostras curadas.

\section{RESULTADOS E DISCUSSÕES}

A cinza pesada utilizada neste trabalho foi escolhida, porque está disponível em grandes quantidades no Sul do Brasil, um fator que favorece a remoção do resíduo de sua origem, para utilização como matéria-prima para o desenvolvimento de novos produtos. A Tabela 1 apresenta os resultados da análise química da cinza pesada, realizado pela técnica de FRX.

Tabela 1. Composição química da cinza pesada em (\%) massa.

\begin{tabular}{lllllllllll}
\hline Oxido & $\mathbf{S i O}_{2}$ & $\mathbf{A l}_{2} \mathbf{O}_{3}$ & $\mathbf{F e}_{2} \mathbf{O}_{3}$ & $\mathbf{C a O}$ & $\mathbf{M g O}$ & $\mathbf{K}_{\mathbf{2}} \mathbf{O}$ & $\mathbf{T i O}_{2}$ & $\mathbf{N a}_{2} \mathbf{O}$ & $\mathbf{P}_{2} \mathbf{O}_{5}$ & P.F. \\
\hline C.P. & 59,8 & 22,6 & 4,5 & 1,3 & 0,5 & 2,3 & 1,1 & 0,4 & 0,2 & 6,6 \\
\hline
\end{tabular}

Os dados da análise FRX demonstram que a cinza pesada contém uma quantidade de $\mathrm{SiO}_{2}$ e $\mathrm{Al}_{3} \mathrm{O}_{2}$ atraente para uso na reação de geopolimerização, pois com base nas pesquisas de Davidovits (2002), os melhores resultados para que ocorra geopolimerização foram obtidos nas proporções molares entre $\mathrm{SiO}_{2} / \mathrm{Al}_{2} \mathrm{O}_{3}$ de 3,3-4,5. O mesmo pesquisador relata que as melhores proporções entre $\mathrm{SiO}_{2} / \mathrm{Na}_{2} \mathrm{O}$ na solução de ativação são próximas de 1,85 . As proporções entre $\mathrm{SiO}_{2} / \mathrm{Al}_{2} \mathrm{O}_{3}$ presentes na cinza pesada (Tabela 1) são próximas dos valores mínimos sugeridos.

A Figura 2 apresenta micrografias de amostras geopoliméricas, sintetizadas com cinza pesada pura, após 90 dias de cura. A Figura 2a e 2b apresentam aumentos de 100 e 1000 vezes, respectivamente, micrografada a partir de uma amostra fraturada. Através das imagens é possível observar que os materiais possuem muitos pontos de geopolimerização, porém, apesar de densa, a estrutura apresenta algumas rachaduras. A Figura 2c apresenta uma micrografia da superfície da amostra, onde é possível observar algumas rachaduras e alguns pontos de carbonatação. A carbonatação é um processo que pode ocorrer devido ao excesso de sódio, que é arrastado para a superfície e, em contato com o gás carbônico do ar, forma carbonato de sódio. Através da análise de EDS é possível identificar os principais componentes existentes nos geopolímeros (Rattanasak et al., 2009). Na Figura 2d foi possível 
identificar a presença de $\mathrm{Si}, \mathrm{Al}, \mathrm{Na}, \mathrm{O}$ e $\mathrm{Ca}$.

É importante salientar que as cinzas pesadas são constituídas por partículas ocas que reagem quando parcialmente ativadas formando uma matriz porosa. A estrutura porosa deve ser controlada, pois a água pode penetrar na estrutura por ação capilar e sorção, e esses efeitos são prejudiciais para a durabilidade do material (Olivia et al., 2008). O uso de outro material menos poroso, em conjunto com a cinza pesada, pode minimizar esses defeitos estruturais.

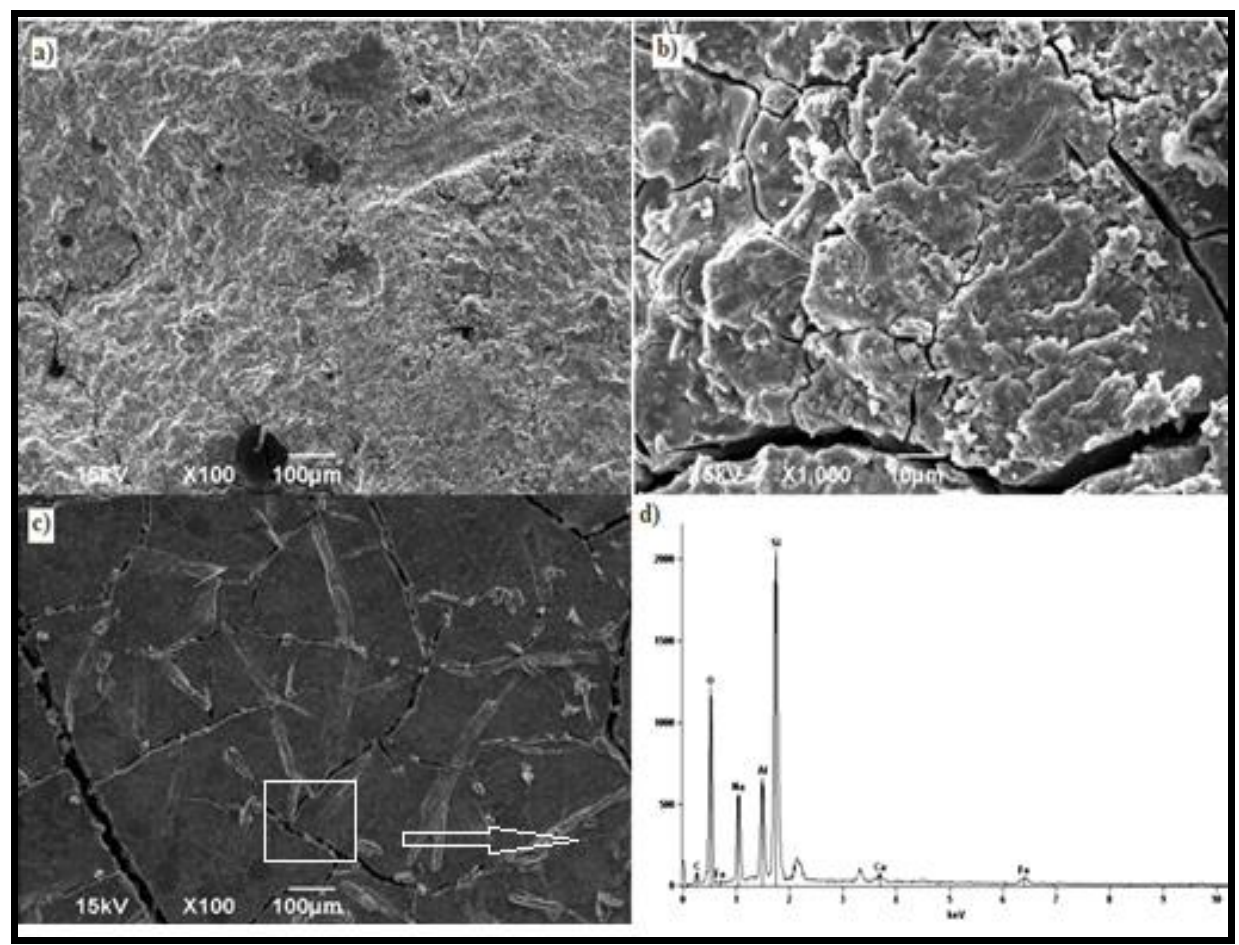

Figura 2: Micrografias de amostras geopoliméricas após cura de 90 dias; (a) fratura, b) detalhe da fratura, c) superfície, d) análise quantitativa por EDS (obtido a partir de uma determinada região).

A Figura 3 refere-se à análise de DRX de cinza pesada antes da ativação. O halo que aparece no difratograma entre $2 \theta=18^{\circ}$ e $2 \theta=35^{\circ}$ é típico de um material não cristalino (Panias et al., 2006; Fernandez-Jiménez e Palomo, 2005). É possível também observar que a cinza pesada possui alguns picos identificados como quartzo, mulita, hematita, magnetita, entre outros, referentes a partículas cristalinas. A estrutura da cinza pesada é alterada durante o processo de geopolimerização, conforme pode ser observado no difratograma da Figura 4, referente à amostra geopolimérica, sintetizada com $15 \mathrm{M}$. Alguns picos cristalinos sofrem alteração, ficando um pouco menores, quando comparados com os picos do difratograma da cinza pesada. O halo da estrutura amorfa após a ativação alcalina fica maior e ocorreu mudança no ângulo, evidenciando a transformação do material após a geopolimerização. As mudanças na estrutura dos materiais geopoliméricos, em relação a cinza pesada, foram promovidas por cátions dos metais presentes na solução alcalina. A solução ativadora destrói a estrutura da cinza pesada, transformando-a em gel de aluminossilicato de sódio (Mendonça, 2007).

O material cristalino presente na cinza pesada permanece apenas como um material de 
enchimento no interior da estrutura geopolimérica, pois não participam na reação de polimerização, a maior reação ocorre na parte amorfa do material, tal como mencionado no presente estudo.

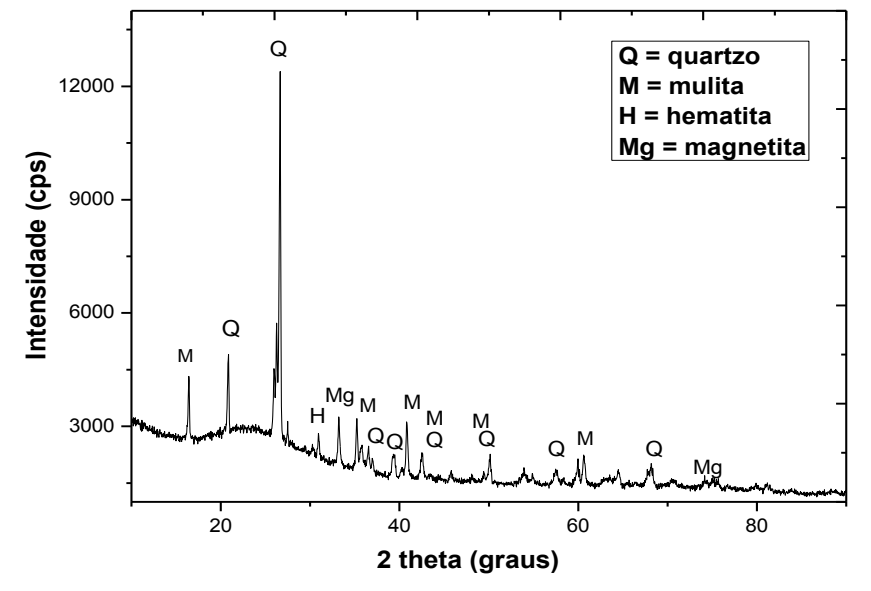

Figura 3: Difratograma da cinza pesada antes da ativação

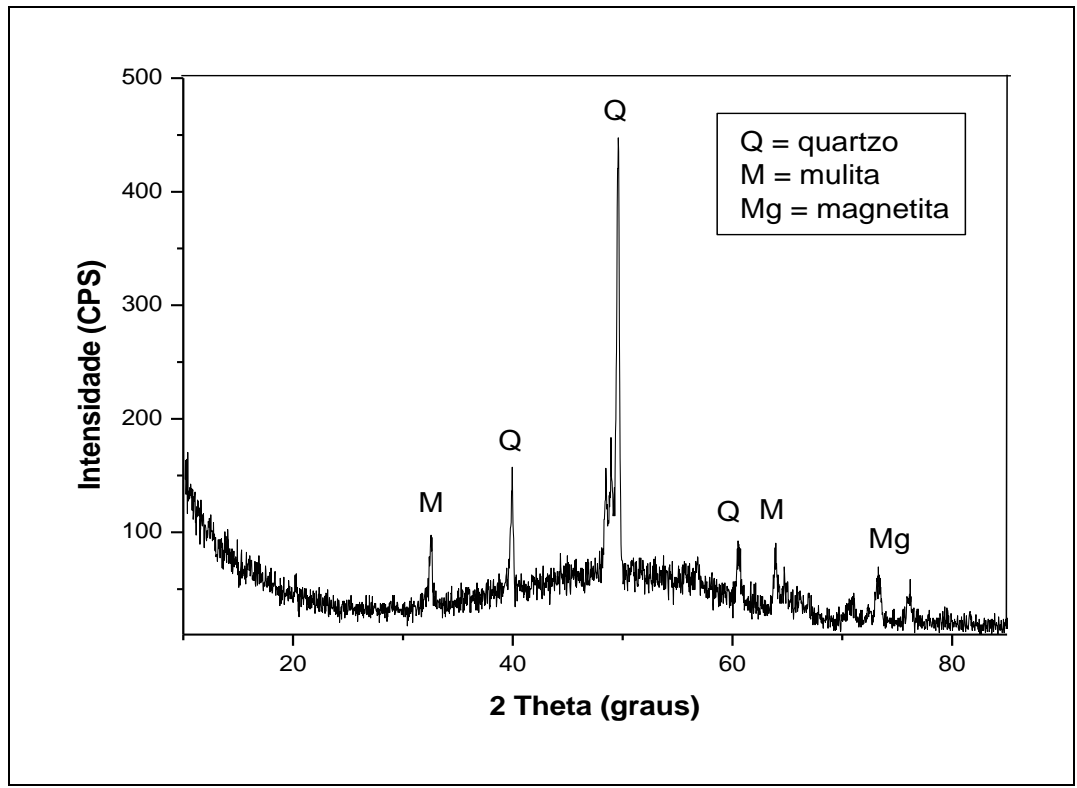

Figura 4: Difratograma do material geopolimérico ativado com $15 \mathrm{M}$ de $\mathrm{NaOH}$.

As variações que ocorrem entre os materiais sólidos utilizados e os reagentes selecionados para a ativação alcalina vai definir a formação da matriz do polímero inorgânico, e resultar na microestrutura, e nas propriedades físicas, mecânicas e químicas do material (Duxson et al., 2006). De acordo com alguns investigadores, a fim de obter o processo de geopolimerização satisfatório, deve-se avaliar a correspondência entre as razões molares dos materiais sólidos, com base em aluminossilicatos, e as proporções molares entre os ativadores utilizados (Duxson et al., 2006; KonmitsaS et al., 2007; Pinto, 2004). 
A cinza pesada possui em sua microestrutura proporções de material amorfo disponível para ser ativado e polimerizado para formar novos materiais, no entanto, o tempo de cura das amostras em temperatura ambiente demonstrou ser muito maior em relação a outras matériasprimas, ricas em aluminossilicatos, que passaram por ativação alcalina (Boca Santa, 2012). O tempo de cura é de importância fundamental para definir a colocação, transporte e compactação dos materiais cimentícios (Pinto, 2004). O tempo de pega normalmente demora cerca de 90 minutos e, em aproximadamente 4 horas, a matriz sofre endurecimento. $\mathrm{O}$ atraso no tempo de cura, que ocorreu nas amostras sintetizadas com cinza pesada pode ser devido à maior proporção da parte cristalina na microestrutura da cinza pesada e menor teor de material amorfo reativo (Fernandez-Jimenez et al., 2004).

Para realizar os testes de resistência à compressão, foram produzidas duas amostras para cada tempo de cura da pasta geopolimérica. Os tempos de cura foram 30 e 90 dias. Os resultados obtidos com a pasta geopolimérico foi de $1,87 \mathrm{MPa}$, durante 30 dias e $6,8 \mathrm{MPa}$, durante 90 dias. É importante salientar que as amostras foram sintetizadas sem agregados finos ou grossos. Os resultados referentes à resistência à compressão podem ser melhorados, dependendo das condições de síntese, matéria-prima, ativador alcalino, molaridade, temperatura e outras variáveis que podem influenciar os resultados finais do processo.

\section{CONCLUSÃO}

O uso de cinzas pesadas para síntese de geopolímeros apresentou resultados satisfatórios. As micrografias obtidas por MEV e os resultados da análise de DRX indicaram a ocorrência de geopolimerização. Os resultados de resistência à compressão foram condizentes com a literatura, por se tratar apenas de uma pasta sem agregados, e curadas em temperatura ambiente.

Após a caracterização da cinza pesada e a síntese de algumas amostras geopoliméricas, pode concluir-se que a cinza pesada pode ser utilizada para a produção de materiais geopoliméricos, no entanto, durante a combustão do carvão, parte da cinza pesada sofre cristalização, deixando apenas uma parte no estado amorfo. A cinza pesada deve ser a melhor avaliada, devido ao longo tempo que foi necessário para a cura. Porém, com alguns ajustes, como por exemplo, acrescentando outra fonte de material reativo rico em aluminossilicato, a geopolimerização pode ser uma alternativa muito favorável para dar um destino adequado, economicamente viável e ambientalmente correto, ao elevado volume de cinza pesada gerada durante o processo de queima do carvão para produção de energia elétrica. Atualmente grande parte da cinza pesada é misturada aos cimentos tradicionais, no entanto, os materiais geopoliméricos possuem muitas propriedades iguais ou superiores aos cimentos comuns e são produzidos com pouco gasto energético por não necessitar do processo de clinquerização para sua produção.

\section{AGRADECIMENTOS}

Coordenação de Aperfeiçoamento de Pessoal de Nível Superior (CAPES / DS).

\section{REFERÊNCIAS}

BOCA SANTA, R. A. A., Desenvolvimento de Geopolímeros a partir de Cinzas Pesadas 
Oriundas da Queima do Carvão Mineral e Metacaulim a partir de Resíduos da Indústria de Papel. Dissertação, Universidade Federal de Santa Catarina, Florianópolis, 2012.

DAVIDOVITS J.; 30 Years of Successes and Failures in Geopolymer Applications. Market Trends and Potential Breakthroughs. Keynote Conference on Geopolymer Conference Melbourne, Australia, 2002.

DUXSON, P; FERNANDEZ J.; PROVIS, J.L.; Geopolymer Technology: the Current State of the Art. Advances in Geopolymer Science \& Technology, Springer Science+Business, v.42, p. 2917-2933, 2006.

FERNÁNDEZ-JIMÉNEZ, A.; PALOMO, A.; CRIADO, M.. Microstructure Development of Alkali-Activated Fly Ash Cement: a Descriptive Model. Cement And Concrete Research, Madrid, p.1204-1209, 2004.

FERNÁNDEZ-JIMÉNEZ, A.; PALOMO, A., Composition and Microstructure of Alkali Activated Fly Ash Binder: Effect of the Activator. Cement And Concrete Research, Madrid, p.1204-1209, 2005.

GAVRONSKI J. D., Carvão Mineral e as Energias Renováveis no Brasil. Tese de Doutorado, Universidade Federal Rio Grande do Sul, Porto Alegre- RS, 2007.

KOMMITSAS K., ZAHARAKI D.; Geopolymerisation: A Review and Prospects for the Minerals Industry. Minerals Engineering, v. 20, p. 1261-1277, 2007.

MENDONÇA, C. M. D.; Activação Alcalina de Resíduos Industriais. Dissertação de Mestrado, Departamento de Engenharia Cerâmica e do Vidro, Universidade de Aveiro. p. 116, 2007.

OLIVIA, M.; SARKER, P.; NIKRAZ, H.; Water Penetrability of Low Calcium Fly Ash Geopolymer Concrete. Conference on Constituction and Building Technol International, 2008.

PANIAS, D.; GIANNOPOULOU, I. P.; Development of Inorganic Polymeric Materials Based on Fired Coal Fly Ash. Acta Metallurgica Slovaca, v. 12, P. 321 - 327, 2006

PINTO T. A., Novos Sistemas Ligantes Obtidos por Activação Alcalina. Construção Magazine. Tese de Doutorado da Universidade de Minho, Portugal 2004.

RATTANASAK U., CHINDAPRASIR P.T.; Influence of $\mathrm{NaOH}$ Solution on the Synthesis of Fly Ash Geopolymer. Minerals Engineering, v.22, n. 12, 2009.

TORGAL F. P.; JALALI, S.. Dossier Eco-Eficiência. Materiais de Construção. Disponível em: < http://www.apcmc.pt/newsletter/newsletter_n178/imagens/dossier_ecoeficiencia.pdf>. Acesso em: 25 de maio de 2011. 